\title{
Habitat fragmentation reduces occupancy of nest boxes by an open-country raptor
}

\author{
JESSI L. BROWN, MICHAEL W. COLLOPY and JOHN A. SMALLWOOD
}

\begin{abstract}
Summary
Despite the recent rapid decline of many grassland bird species, the relative importance of habitat configuration to population persistence is unclear. We used Southeastern American Kestrels Falco sparverius paulus in north-central Florida as a model system to explore the relative influence of landscape structure components on site occupancy patterns at two spatial scales, and for two different time periods. We focused on the dynamic processes of site-level population expansion or contraction. We modelled the occupancy of 131 American Kestrel nest boxes with Bayesian state-space dynamic occupancy models that considered both the partially observed process of true occupancy and the probability of detection of occupancy. We used reversible jump Markov chain Monte Carlo (RJMCMC) algorithms to identify variables that described the continued occupancy of nest boxes, or $\phi$, and the probability of colonisation of nest boxes between time periods, or $\gamma_{3}$. Changes in open habitat patch isolation at a fine scale, as estimated by the variability of nearest neighbour distance, predicted site colonisation between decades, and patch shape variability was related to $\phi$ during the early time period (1992-93). We found no strong effects of landscape structure on $\phi$ during the later time period (2008-2010). We also found no evidence for effects of loss of open habitat on box occupancy or colonization. Our results indicate that continued habitat fragmentation would be deleterious for this threatened subspecies. Additionally, certain land cover management practices recommended for the Florida sandhills, such as frequent low-intensity controlled burns, will likely help conservation attempts.
\end{abstract}

\section{Introduction}

Observed changes in animal distribution and abundance are frequently attributed to changes in land cover or habitat composition across their range (Herkert 1994, Flather and Bevers 2002). Patches of preferred habitats can be lost outright, or the shape and configuration of preferred habitat patches can change, with the two processes often closely linked (Fahrig 2003, Fletcher Jr. et al. 2007). A growing body of literature suggests that certain species respond strongly to changes in preferred habitat extent, whereas other species may be more sensitive to landscape context such as habitat fragmentation or patch isolation (Watling and Donnelly 2006, Prugh et al. 2008). Additional complexity can arise from responses to land cover changes at different scales, and sometimes multiple scales simultaneously (Cunningham and Johnson 2006, Desrochers et al. 2010). Despite the application of various theories to explain observed changes in patterns, such as the area-per-se effect or source-sink dynamics (Connor and McCoy 1979, Pulliam 1988), proper evaluation of these theories has been complicated by the majority of studies having focused on a few taxonomic groups and habitats. Studies of area sensitivity, focal patches, and matrix composition effects have most frequently used birds in the order Passeriformes as model systems (Bayard and Elphick 2010, Thornton et al. 2011, Watling et al. 2011). Preferred habitat types have not received equal attention: for example, most studies of avian area sensitivity focused on forest 
habitat types (75\%), with fewer on more open habitats such as grasslands (12\%) and scrub $(5 \%)$ (Bayard and Elphick 2010).

The relative lack of studies on the effects of land cover change and fragmentation in grassland and other open habitat systems is particularly surprising given the conservation concerns for grassland-associated species, especially birds. Grassland and open savanna bird species are widely recognised to be in particular danger from land cover alteration in various forms, from afforestation of formerly open habitats in the eastern USA to degradation of prairies by overgrazing and conversion to row crop agriculture (Brennan and Kuvlesky Jr. 2005). Many of the bird species dependent on the pine savannas that once covered over 25 million ha of the south-eastern USA are considered part of this threatened group, as the grass stratum of this historically open habitat can function similarly to grasslands lacking a tree overstorey (Myers and Ewel 1990). However, the mechanisms driving the loss of these birds are poorly understood (Askins et al. 2007, Ribic et al. 2009).

Throughout Florida, USA, open habitats such as sandhill and dry prairies host many taxa that are considered threatened, such as Sherman's fox squirrels Sciurus niger shermani, Florida grasshopper sparrows Ammodramus savannarum floridana, Southeastern American Kestrels Falco sparverius paulus, and gopher tortoises Gopherus polyphemus. Sandhill habitat loss began during European settlement and continues through present times; from 1985-1989 to 2003, 53,356 ha or $15.5 \%$ of Florida's sandhill habitat was lost, with $72 \%$ of this converted to urban or other developed uses (Florida Fish and Wildlife Conservation Commission 2005, Kautz et al. 2007). Concurrent with sandhill habitat loss, the Southeastern American Kestrel was determined to have declined by at least $82 \%$ in north-central Florida in the mid-1980s, and is currently considered a Species of Greatest Conservation Need (Hoffman and Collopy 1988, Collopy 1996, Florida Fish and Wildlife Conservation Commission 2005). Because the occurrence of the Southeastern American Kestrel in Florida is putatively linked to sandhill habitat, changes in the distribution of this easily detected bird might provide a clearer picture of the impacts of coarse-scale habitat change on grassland or pine savanna animal populations. We proposed using kestrels as a model system to compare the influence of loss of open habitats to habitat fragmentation and changes in landscape context on wildlife distribution.

A substantial population of kestrels uses an extensive nest box network near Gainesville, FL and presents an opportunity to gain insight into the dynamics of their habitat use (Smallwood and Collopy 2009). Records of nest box occupancy begin in the early 1990 and continued through the present. Published land cover maps represent conditions during both the early period of the project and more recent times, and document the rapid urbanisation and land cover change of the study region (Kautz et al. 2007). We chose to consider the dynamic occupancy patterns of kestrel nest boxes over time and land cover change. Bayesian state-space occupancy models explicitly address both the occupancy state of the sample site and the detection probability of the focal organism in that site, conditional on the site being truly occupied (MacKenzie et al. 2003, Royle and Kery 2007). Incorporating detection probability is particularly important, as site occupancy probabilities will be biased low if imperfect detection is unaccounted for (Royle and Dorazio 2008). We modelled occupancy by considering the initial occupancy state of our sample sites $(\psi)$, and then modelling the probability of continued occupancy ( $\phi$, "survival") of those sites and the probability of colonisation of vacant sites $(\gamma)$ over time. Separating the occupancy pattern into $\phi$ and $\gamma$ allowed us to examine the possible influences of habitat covariates on each component.

American Kestrels are known to be raptors of open habitats, so we hypothesised that they would respond negatively to loss of sandhill and other open habitats (Smallwood and Bird 2002). Because the extent of sandhill habitat has decreased throughout Florida since the initiation of the kestrel nest box project, we predicted that some boxes which were once located in sandhill habitat were likely to be surrounded by less suitable habitats later, with the net result that the overall occupancy rates of nest boxes will have decreased over time. However, it is unclear whether all forms of sandhill conversion are detrimental to kestrels. Longleaf pine Pinus palustris trees or other nest sites are necessary for kestrel reproduction, and their removal from agricultural fields 
was linked to loss of breeding kestrels (Hoffman and Collopy 1983, 1987). Kestrel presence, however, appeared little affected by mechanical or fire restoration treatments of sandhill forest patches, as they prefer open pastures, clear-cuts, and natural clearings within sandhill habitat (Bohall-Wood and Collopy 1986, Provencher et al. 2002). Therefore, we hypothesised that the probability of nest box occupancy would be less strongly correlated with open habitat patch fragmentation than with habitat loss per se.

\section{Methods}

\section{Study area}

We studied American Kestrels in 1992-1993 and 2008-2010 using a network of 131 nest boxes first placed in north-central Florida during 1990-1991 (Smallwood and Collopy 2009). Our study area fell within Levy and Marion counties, and was centred on approximately $29^{\circ} 21^{\prime} \mathrm{N}, 82^{\circ} 23^{\prime}$ W (Figure 1 ). Habitat immediately surrounding nest box locations generally could be classified as either hammock, characterised by laurel oak Quercus laurifolia and live oak Q. virginiana, or sandhill. Sandhill is a xeric upland vegetation community dominated by longleaf pine and turkey oak Q. laevis with a ground cover of wiregrass Aristida stricta that is characterised by an open, park-like structure (Myers and Ewel 1990). Most of the nest boxes were maintained continuously throughout the study. However, in summer 2008, we replaced 32 boxes at historical locations where the boxes had disappeared. Nest boxes were constructed from $2.5-\mathrm{cm}$ cedar or cypress lumber and placed $6-7 \mathrm{~m}$ high on roadside utility poles or live trees (further details in Appendix $\mathrm{S}_{1}$ and Figures $\mathrm{S}_{1}-\mathrm{S}_{2}$ in the online Supplementary Materials).

\section{Field methods}

Each year in February, all nest boxes were first visited, cleaned, repaired, and filled with a 5-cm layer of wood shavings. Box occupancy status was determined by direct observation of box contents at 3-4 week intervals in 1992-1993, and at $\leq 10-d$ intervals in 2008-2010. Boxes were considered occupied only if either eggs or nestling kestrels were found, even though adult kestrels may have been detected in the area. We checked most boxes through July or August, but here we consider observations between March and June as the majority of nesting attempts were initiated in these months (Smallwood and Bird 2002). Research and handling protocols (\#00329) were reviewed and approved by the Institutional Animal Care and Use Committee at the University of Nevada, Reno.

\section{Land cover change analysis}

Changes in land cover throughout the study area were assessed by analysis of published land cover maps roughly corresponding to the initiation of the nest box project ("early") and the later monitoring project ("late") in a geographical information system (GIS). Maps of vegetation and land cover at 30-m resolution were developed by the Florida Fish and Wildlife Commission from classification of Landsat Thematic Mapper satellite imagery (Kautz et al. 2007). The first map depicted 17 natural and semi-natural land cover types and four anthropogenic land cover types, based on imagery acquired between 1985 and 1989 . The second map was produced by a similar process, but updated the land cover map by interpretation of imagery from 2003 into 44 land cover types. Although the source imagery did not exactly match the periods of our study, we assumed that the landscape changes documented by this imagery were representative of the patterns of changes during our study. We reclassified the two maps using the Kautz et al. (2007) common reclassification scheme of land cover types into 17 categories to allow direct comparisons (Appendix $\mathrm{S}_{1}$ and Table Si).

Configuration and form of habitats thought to be important to kestrels in the reclassified maps were quantified in the program FRAGSTATS (McGarigal et al. 2002). Moving window analyses 


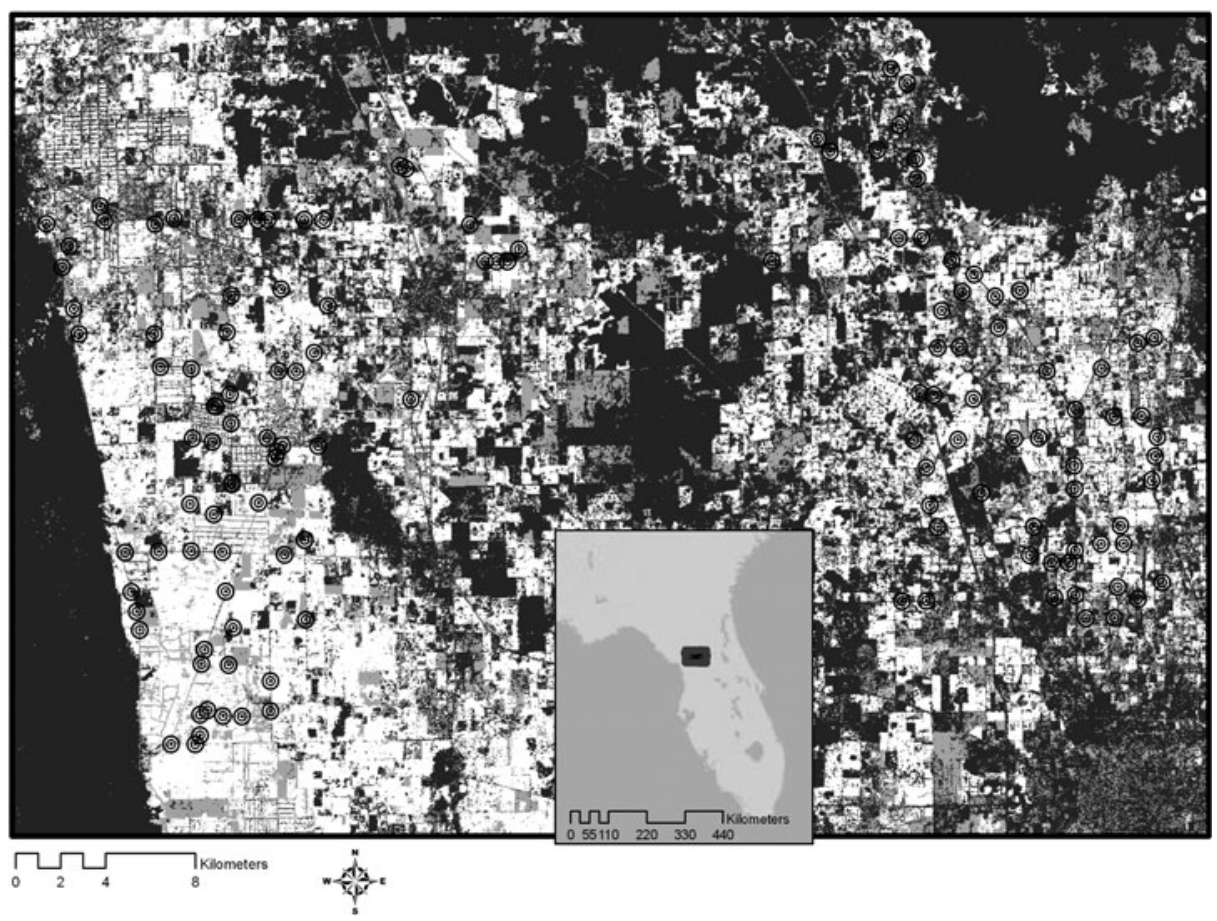

Figure 1. Conversion of open habitats (combined land cover types of sandhill and grassland/ agriculture) from 1985-1989 to 2003 in north-central Florida, USA. White indicates land cover that was open habitat in both time periods, light grey indicates land cover that was previously open habitat but changed to a different land cover type, and dark grey indicates land cover that was not previously open habitat and remained so. Locations of American Kestrel nest boxes shown by circles.

generated class and landscape metric surfaces that integrated landscape characteristics at two biologically relevant scales, reflecting a potential home range size ( $1-\mathrm{km}$ diameter circle) and median natal dispersal distance (4.9-km diameter circle) respectively (Miller and Smallwood 1997, Smallwood and Bird 2002). Metrics were selected to represent universal and highly consistent components of class-level and landscape-level structure as identified by Cushman et al. (2008). Values of these metrics were extracted at each nest box point location with ArcGIS 1o software by ESRI. Collinearity between the metrics was assessed by Pearson's correlation coefficients, and those metrics that were highly correlated with others and less straightforward to interpret were not retained for analysis in the occupancy models (final sets of metrics in Table 1 , equations for metrics Appendix SI).

We also wished to examine whether the amount per se of the putative preferred open habitat influenced kestrel box occupancy patterns. We therefore assessed the potential influence of the proportion of the landscape covered with open habitat (PLAND_5) at the coarse scale in the final iteration of the modelling process (see below). We could not assess PLAND_5 during the earlier modelling stages as the variable was strongly correlated with many of our chosen metrics, but it was only weakly correlated with the set of metrics selected for the final iteration. Values of PLAND_5 at the two scales were highly correlated, and so after a preliminary analysis, we chose to include the variable at the coarse scale because the influence of the variable on occupancy at this scale was greater. 


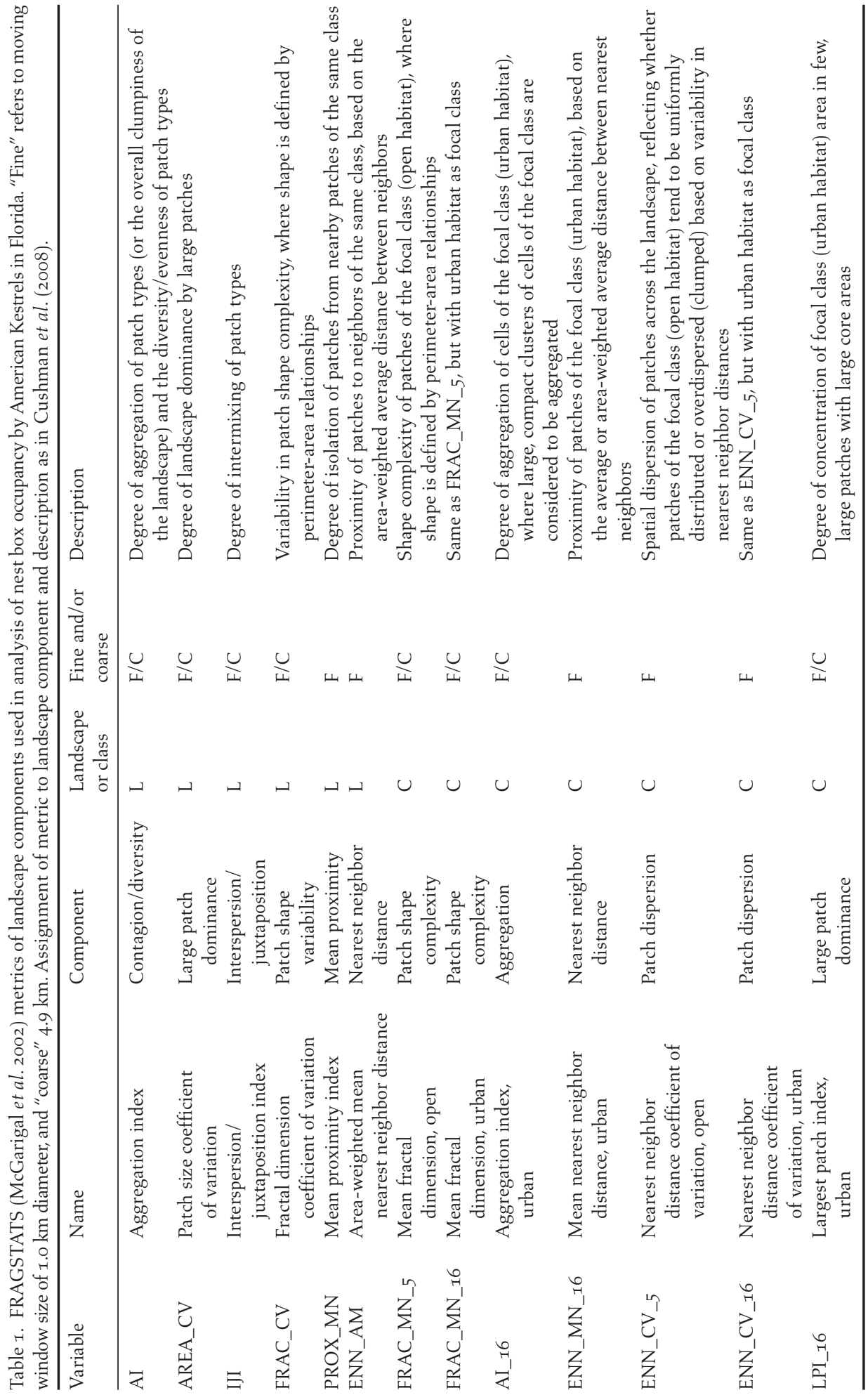




\section{Dynamic occupancy models}

We assessed the potential importance of the FRAGSTATS-derived landscape metrics to kestrel nest box occupancy patterns with dynamic occupancy models in R 2.12.1 and WinBUGS 1.4.3, using the R package "R2WinBUGS" (Lunn et al. 2000, Sturtz et al. 2005, R Development Core Team 2010). Sample code is provided in Appendix S2. A detection history $(y(i, j, t))$, directly analogous to an encounter history in a mark-recapture analysis, was generated for each nest box in which "O" indicated that kestrels were not using that particular box, $i$, and " $I$ " was recorded when evidence of kestrel breeding activity (eggs or nestlings) was found during survey $j$ of year $t$. Similar to robust design mark-recapture models, the encounter history of boxes within each season contributed to the estimation of the probability of detecting kestrel breeding activities, because each breeding season was considered a primary sampling period, and each month within the breeding season a secondary sampling period (Pollock 1982). Because visit frequency varied across and within years, we downsampled our detection histories to monthly sampling periods, with any one detection within that month sufficient to count the nest box as occupied. If nest boxes were not checked during any particular month, either because of field personnel schedules or box unavailability, the occupancy status for that month was recorded as missing.

With multiple primary sampling periods, two additional parameters can be estimated to represent the probability of a previously unoccupied box being used for kestrel breeding ( $\gamma$ or "colonisation") and the probability that a box that had hosted kestrels was occupied again the following year ( $\phi$, or "survival"). The dynamic occupancy model is therefore composed of two component processes: the observation model that is conditional on the state process of occupancy, $y(i, j, t) \mid z(i, t)$, and the state model that is only partially observed $z(i, t)$ with $z=1$ if the site is occupied or o if it is not. The initial occupancy vector is a Bernoulli random process of the initial occupancy probability $\psi_{1}$ for sites i through $\mathrm{R}$

$$
z(i, 1) \sim \operatorname{Bernoulli}\left(\Psi_{1}\right) \text { for } i=1,2, \ldots, R
$$

and in the following primary periods

$$
z(i, t) \mid z(i, t-1) \sim \text { Bernoulli }\left\{z(i, t-1) \phi_{i, t}+[1-z(i, t-1)] \gamma_{i, t}\right\}
$$

for years $t=2,3, \ldots, \mathrm{T} ; \phi_{\mathrm{i}, \mathrm{t}}$ as the local survival probability, and $\gamma_{\mathrm{i}, \mathrm{t}}$ as the colonization parameter. The observation model here is given by

$$
y(i, j, t) \mid z(i, t) \sim \text { Bernoulli }\left[z(i, t) p_{i, j, t}\right]
$$

with $p_{i, j, t, t}$ the probability of detection, given the site $i$ is occupied and nesting activity observed during survey $\mathrm{j}$ at year $t$. Because kestrels were resident in their breeding areas year-round, but evidence of breeding was only present seasonally, we modelled $p$ separately using a logit link to a covariate that varied by both month $j$ and year $t$.

Because animals are thought to assess and select habitat by a hierarchical process, but the relative importance of scales is unclear, we examined predictor variables for occupancy at multiple scales both separately and concurrently (Wiens 2000). Changes in metrics at nest box locations between early and late time periods were assessed by subtracting the metric value in the early part of the study from that calculated for the late time period. We assessed models iteratively, by first examining the potential coarse-scale influences on occupancy, then assessing fine-scale covariates, and finally comparing a combination of the best-performing variables from each scale. Models from each step of the process were selected by examining the marginal posterior probability of each variable as estimated by reversible jump Markov chain Monte Carlo 
(RJMCMC) algorithms implemented through the WinBUGS JUMP interface (Lunn 2007, Lunn et al. 2009). The survival and colonisation parameters of the occupancy models were parameterised to include covariates through a logit link. Here, we specified that

$$
\operatorname{logit}\left(\phi_{i, t}\right)=\alpha_{t}+\nu_{i}
$$

and

$$
\operatorname{logit}\left(\gamma_{i, t}\right)=\beta_{t}+\eta_{i}
$$

where $\alpha_{t}$ and $\beta_{t}$ were the fixed year intercepts for each year interval, and $v_{i}$ and $\eta_{i}$ were nodes linking the logit statements to the RJMCMC components (see next section).

We coded three separate RJMCMC routines into the dynamic occupancy models. We examined the effects of metrics that described the early land cover on $\phi_{\mathrm{i}, 2}$, or site survival during the early time period, the effects of those metrics that described land cover later on $\phi_{\mathrm{i}, 5}$, and the effect of the change in landscape metrics on $\gamma_{\mathrm{i}, 3}$, or the probability of colonization between study time periods. All predictor variables were standardised to means of zero and unit variance. The RJMCMC routines were free to update and assess the effects of their covariate configuration, while the other RJMCMC routines simultaneously updated and assessed their portions of the model. Those variables with any suggestion of an effect (marginal posterior probability of that variable $>0.6$ ) at either of the spatial scales were assessed in the multi-scale model, along with the PLAND of open habitat. Individual variables with high marginal posterior probabilities $(>0.70)$ as estimated through RJMCMC were considered potentially influential, and the posterior probability of their beta coefficients examined for lack of overlap with zero.

All prior probabilities were selected to be uninformative (Appendix A.I). For each model, we ran two chains for 175,000 iterations, discarding the first 75,00o runs as burn-in. Convergence was assessed by visual inspection of the model trace, and the Raftery-Lewis and Gelman-Rubin diagnostic tests implemented in the R package "coda" (Plummer et al. 2006). Final predicted parameter values were generated by simulations from a final model that contained only the variables deemed important by the iterative process. As a final step, we generated predicted finite-sample annual turnover, annual growth rates, occupancy rates, and values of early $\phi$ or $\gamma$ for different values of important variables. The finite-sample estimates consider the actual sample observed, rather than a theoretically infinite population of sites represented by our sample, with resulting expected values equivalent to those of the population parameters but with higher precision (Royle and Kery 2007). Thus, for the sample of $R$ sites for year $t$, the finite-sample estimate of occupancy is

$$
\psi_{t}^{(f s)}=\frac{1}{R} \sum_{i} z(i, t)
$$

Sample turnover rate, or the probability that an occupied site picked at random is newly occupied, is

$$
\tau_{t}^{(f s)}=\frac{\sum_{i=1}^{R}[1-z(i, t-1)] z(i, t)}{\sum_{i=1}^{R} z(i, t)}
$$

The sample growth rate, or change in overall occupancy from one year to the next, is

$$
\lambda_{t}^{(f s)}=\frac{\sum_{i=1}^{R} z(i, t+1)}{\sum_{i=1}^{R} z(i, t)}
$$

Final parameter estimates are presented as means of the posterior probability distributions with $95 \%$ Bayesian credible intervals. 


\section{Results}

\section{Changes in land cover between time periods in study area}

The land cover type, disregarding rare types such as scrub and salt water marsh, which decreased the most between time periods was pineland (Table 2). However, when we examined the maps visually, we saw that large areas that were originally classified as pineland were later classified as upland forest. Because we suspected that the change in classification was arbitrary and not reflective of differences in land cover structure, we considered land cover change when those two categories were combined. The land cover type with the greatest decrease over time both in overall area (loss of $9583.02 \mathrm{ha}$ ) and original extent (loss of $91 \%$ ) was open habitat, the type of land cover expected to be important to kestrels (Figure 1, Table 2). The land cover types that increased the most in absolute area were shrub and brushland, the combined category of pineland and upland forest, and forested wetlands. Analysis of the entire study area in FRAGSTATS confirmed that the percentage of the study area covered by open habitat decreased over time (PLAND of early map $=40.60$, PLAND of later map $=36.96$ ), and also suggested that the open habitat land cover became more disaggregated across the landscape (IJI of early map $=57.77$, IJI of late map $=65.25)$. However, the overall fractal shape complexity decreased somewhat (PAFRAC early $=1.54$, PAFRAC late $=1.47$ ), and there was no major change in landscape level contagion (CONTAG early $=42.75$, CONTAG late $=43.04$ ).

\section{Coarse- and fine-scale landscape influences on nest box occupancy}

At the scale of kestrel natal dispersal, results based on dynamic site occupancy modeling suggested that interspersion and juxtaposition of land cover types as well as large patch dominance of urban habitat patches (IJI and LPI_I6) were associated with continued site occupancy, or $\phi$, during the early period, and that the change in aggregation of urban habitat (AI_I6) may have influenced $\gamma$, or colonization of sites between time periods (Table $\mathrm{S}_{2}$ ). The only variable with weak influence on $\phi$ late was patch shape complexity of open habitat (FRMN_5; Table S2)

At the scale of a kestrel home range, patch shape variability (FRAC_CV) was related to $\phi$ in the early time period, whereas decreases in the proximity of patches to neighbours of the same class (ENN_AM) were associated with decreases in $\phi$ in the late time period (Table S2). The dispersion of open habitat patches (ENN_CV_5) was weakly associated with $\gamma$ between decades.

Table 2. Changes in extent of land cover types within study area in northern Florida, USA. Area classified per type from the early time period (1985-89), late (2003), and change between time periods are reported in hectares. "\% Extent" is the area covered by the land cover type in the later period divided by the area covered in the earlier period multiplied by 10o. Certain large regions that were classified earlier as pineland were later classified as upland forest without apparent change in true land cover, so pineland and upland forest were combined to better illustrate land cover change.

\begin{tabular}{|c|c|c|c|c|}
\hline Land cover class & Early & Late & Change & $\%$ Extent \\
\hline Dry prairie & o & 1753.02 & 1753.02 & $\mathrm{n} / \mathrm{a}$ \\
\hline Pineland & 51435.27 & 41134.59 & -10300.68 & 80 \\
\hline Scrub & 440.37 & 3.69 & -436.68 & 1 \\
\hline Open habitat & 106818.48 & $97235 \cdot 46$ & -9583.02 & 91 \\
\hline Upland forest & 24968.61 & $37847 \cdot 79$ & 12879.18 & 152 \\
\hline Forested wetland & 11239.92 & 13330.44 & 2090.52 & 119 \\
\hline Salt marsh & 0.09 & $\mathrm{O}$ & -0.09 & o \\
\hline Freshwater marsh & 10368.99 & 10493.19 & 124.2 & 102 \\
\hline Shrub swamp & 2823.57 & 2970 & 146.43 & 105 \\
\hline Shrub and brushland & 17308.35 & 21161.61 & 3853.26 & 123 \\
\hline Urban/barren & 30673.53 & 31728.69 & 1055.16 & 103 \\
\hline Water & 7008.12 & 5426.82 & -1581.3 & 77 \\
\hline Pineland and upland & 76403.88 & 78982.38 & 2578.5 & 103 \\
\hline
\end{tabular}




\section{Assessment of influences at both scales}

None of the better-performing variables from the previous models or the proportion of putative suitable habitat (PLAND) were influential on late $\phi$, but there was moderate support for the influence of fine-scale patch shape variability (FRAC_CV, fractal dimension coefficient of variation), on early $\phi$ (marginal posterior probability of the variable $=0.732$; Table $S_{2}$ ). As patch shape variability increased, the probability of continued occupancy decreased (Figure 2A). Similarly, changes in fine-scale dispersion of open habitat patches (ENN_CV_5) influenced $\gamma$ (marginal posterior probability $=0.692$ ), with changes towards increasing clumps of habitat patches associated with decreased probabilities of site colonisation (Figure $2 \mathrm{~B}$ ). When we examined the results of a model containing those variables as covariates, we noted that the beta coefficient for FRAC_CV slightly overlapped o (mean -0.427, 95\% CI -0.951:0.044), but the beta coefficient for ENN_CV_5 did not (mean -1.759, -3.762:-0.272). Occupancy rates were highest and relatively stable during the later time period, with both growth and turnover rates highest during the early time period (Table 3 ).

\section{Discussion}

\section{Influence of habitat fragmentation versus extent on kestrel nest box occupancy}

The extent of the putative preferred open habitat (PLAND) was not influential on $\phi$ or $\gamma$ with the marginal posterior probability of those variables never greater than 0.333 . We found that occupancy persistence at kestrel nest boxes was influenced by the landscape context surrounding the box at a scale corresponding to kestrel territory size. Occupied nest boxes were less likely to remain occupied in the following year when patch shape variability increased (i.e. higher values of FRAC_CV). This effect was only marked during the early period of our study. A metric associated with patch isolation, the variability of nearest neighbour distance between open habitat patches (ENN $\mathrm{CV}_{-}$), was the strongest predictor of site colonization between decades. Neither habitat fragmentation nor open habitat amounts at our coarser scale seemed to influence nest box occupancy.

We found no previous studies that assessed the effects of both landscape configuration and habitat extent on kestrel presence or abundance. A discriminant function analysis of vegetation cover in a 3.14-ha circular plot surrounding kestrel nest boxes in Florida (possibly some of the same boxes included in this study) suggested that those boxes never observed to be occupied were surrounded by more broadleaf deciduous trees, live or laurel oak, buildings and gravel, and fewer cabbage palms Sabal palmetto or longleaf pine (Smallwood and Collopy 2009). Similarly, in New Jersey, nest boxes directly observed to be occupied were in more open areas than others: woody canopy covered $7.5 \%$ of 1 -ha circular plots centred on occupied nest boxes versus $16.4 \%$ of plots surrounding unoccupied nest boxes (Smallwood and Wargo 1997). Both of these studies were conducted at a much finer scale than ours (78.5-ha and 1885-ha plots), and it is plausible that we might find similar indications of the importance of the extent of open habitat at similar scales. However, at both scales and time periods, the percentage of open habitat varied greatly among our plots (fine scale early, mean $=69.7 \%$, range $33.5-99.1 \%$; fine scale late, mean $=67.4 \%$, range $26.7-97.7 \%$ ), so not finding an effect is unlikely to be related to lack of variability between sites.

\section{Occupancy probabilities over time}

Despite the estimated loss of over 9,500 ha of open habitat between 1985-1989 and 2003, we found no evidence for decreasing occupancy probabilities in later years. Instead, occupancy rates were higher during the later period of the study (Table 3). This may reflect a lag time involved in local kestrels finding and deciding to use the nest boxes, as most of them were first available in 1991. Alternatively, longleaf pine snags, which tend to provide suitable nesting cavities, may have continued to become less available throughout the study area, which could have increased the importance of artificial nest boxes (Hoffman and Collopy 1988). We also noted that, except for following the first year, the population growth rate was stable across all years (Table 3 ). 

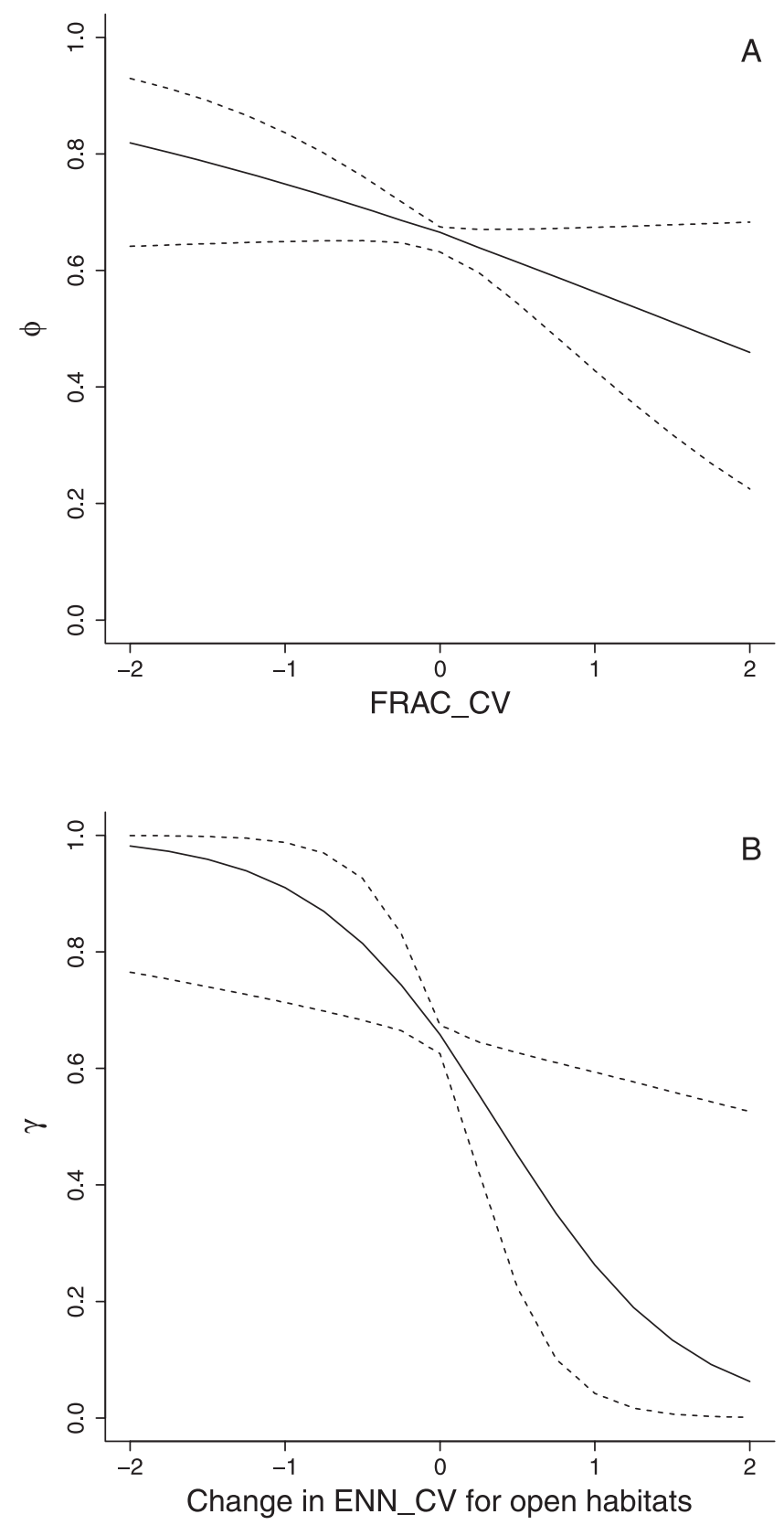

Figure 2. Predicted changes in (A) $\phi$, or "survival" of occupied American Kestrel nest boxes in Florida, and (B) $\gamma$, or the probability of colonisation of previously unoccupied nest boxes in relation to changes in land cover configuration. Increased land cover patch shape variability (as quantified by the metric FRAC_CV in program FRAGSTATS) was associated with decreasing $\phi$, and $\gamma$ decreased as patches of open habitat became less evenly distributed across the landscape (FRAGSTATS metric ENN_CV for open habitat land cover class). Both effects were noted only at our study's fine scale ( $\mathrm{I} \mathrm{km}$ surrounding the nest box). Estimates are median posterior probabilities with $95 \%$ Bayesian credible intervals indicated by dotted lines. 
Table 3. Posterior probabilities of occupancy probabilities from the top dynamic occupancy model of American Kestrel nest box occupancy in Florida, USA. The finite sample estimate of occupancy probability across the study area is $\psi^{(\mathrm{fs})}$, the finite sample turnover rate is $\tau^{(\mathrm{fs})}$, and the finite sample growth rate is is $\lambda(\mathrm{fs})$. Parameter estimates are medians with $95 \%$ Bayesian credible intervals.

\begin{tabular}{llll}
\hline Year & $\psi^{(\mathrm{fs})}$ & $\tau^{(\mathrm{fs})}$ & $\lambda^{(\mathrm{fs})}$ \\
\hline 1992 & $0.442(0.435-0.466)$ & $\mathrm{n} / \mathrm{a}$ & $\mathrm{n} / \mathrm{a}$ \\
1993 & $0.611(0.603-0.626)$ & $0.504(0.406-0.611)$ & $1.359(1.113-1.699)$ \\
2008 & $0.786(0.741-0.832)$ & $0.385(0.294-0.476)$ & $1.096(0.912-1.272)$ \\
2009 & $0.725(0.702-0.748)$ & $0.312(0.236-0.425)$ & $0.981(0.816-1.166)$ \\
2010 & $0.718(0.695-0.756)$ & $0.318(0.241-0.431)$ & $0.998(0.838-1.189)$ \\
\hline
\end{tabular}

We acknowledge that patterns in occupancy of artificially provided nest boxes may not faithfully reflect habitat-related occupancy patterns of bird populations that lack nest boxes (Møller 1989, Koenig et al. 1992). However, in our system general trends of population growth appear to mirror trends of nest box use by breeding adults. Surveys of kestrel population density conducted at sufficient distance from nest boxes to avoid biases associated with concentration of individual birds at specific nest sites suggested that increasing numbers of breeding kestrels accurately reflected an overall local population increase, and that the eventual density stabilised at a density similar to that in a control site which completely lacked nest boxes (Smallwood and Collopy 2009).

\section{Likely ecological causes of kestrel box occupancy patterns}

Sensitivity to habitat fragmentation may be a result of various, not necessarily mutually exclusive, ecological processes including competition, breeding behaviour, and reproductive success (Ribic et al. 2009). Nest boxes intended for kestrels can be usurped by other birds, such as European starlings Sturnus vulgaris or Eastern Screech-owls Megascops asio, or used as roosts or nests by arboreal mammals such as fox squirrels, grey squirrels Sciurus carolinensis and southern flying squirrels Glaucomys volans. Some of these species may occur at higher abundances in fragmented landscapes, or require various non-open habitats in close proximity. Starlings in particular are known to be associated with anthropogenic habitats, such as urbanisation or livestock (Cabe 1993). Competition could also occur when foraging, but we think this is relatively unlikely as kestrels in Florida are generalist predators, known to consume any small animal prey, including invertebrates such as grubs and grasshoppers, frogs, lizards, birds, and rodents (Collopy 1996). Breeding behaviour may possibly influence sensitivity to habitat fragmentation, as kestrels are territorial birds and may perceive habitat fragmentation as a reduction in territory quality. Therefore, kestrels in poorer condition or of lower quality may tend to occupy sites with fragmented land cover, and be intrinsically less likely to retain these sites year after year.

Habitat fragmentation may well affect reproductive success in kestrels, either through differences in predation or natal or breeding philopatry (Stephens et al. 2003). In many bird species, nest predation is thought to be an important factor influencing life history traits through its influence on fitness (Martin 1995). The predator community is often assumed to increase in response to edge or habitat complexity, but the response is not always known (Chalfoun et al. 2002). In our study system, important known nest predators include rat snakes Elaphe sp., grey squirrels, and mesocarnivores such as raccoons Procyon lotor and house cats Felis catus. It is likely that populations of some of these animals increase along with tree density or urbanisation, but we have no direct measurements of potential predator abundance in our study area. Habitat fragmentation might also increase predation of free-flying adult or immature kestrels, because a known avian predator, Cooper's Hawk Accipiter cooperii, relies on forest cover to hunt effectively (Curtis et al. 2006, Smallwood et al. 2009). Again, we have no data regarding the activity of Cooper's Hawks during our study, but Florida breeding bird atlas records show their presence in both counties, and the US Breeding Bird Survey reports that the species has increased in abundance by $5.57 \%$ 
(95\% CI $=2.69-7.95)$ from 1966 to 2010 (Florida Fish and Wildlife Conservation Commission 2003, Sauer et al. 2011). Factors influencing natal or breeding dispersal have not been well studied in the American Kestrel. Observations of the north-central Florida kestrels suggest a sex bias in breeding philopatry, with female kestrels more likely to switch nest sites between breeding attempts, but no evidence that either sex was more likely to disperse after a failed nesting attempt, which could have linked habitat quality with dispersal (Miller and Smallwood 20o9).

\section{Future directions for research}

Our approach to modelling the dynamic process of kestrel nest box occupancy indicated that Southeastern American Kestrels are sensitive to habitat fragmentation at moderately fine landscape scales. However, the mechanism driving this response is unclear. Establishing whether fragmentation of sandhill habitat in the form of forest or urban intrusion is associated with increasing predation pressure, from predators of nests or adult kestrels, would be helpful for conservation not only of kestrels, but other sensitive species dependent on this open habitat. Another logical next step would be to perform a similar analysis incorporating metrics of habitat extent and fragmentation at an increasingly finer scale, such as 1 - to 3 -ha buffers around the nest box. Such an analysis is complicated by the current lack of fine scale published land cover maps, as well as the relatively uncertain location of some nest boxes during the early period. Although nest boxes were maintained in the general vicinity of the current locations, project workers relocated the nest boxes short distances $(10-50 \mathrm{~m})$ under circumstances such as death of the substrate tree or growth of vegetation to block box access. However, we recorded nest box locations to 3-m accuracy with GPS units in 2008-2010, so finer-scale analyses could be performed using only the later period data.

Site occupancy is only one measure of site use by organisms. A complementary approach would be to model several categories of use by kestrels, such as non-breeding occupancy and breeding occupancy, with similar Bayesian state-space models in a multistate occupancy modeling framework (MacKenzie et al. 2009). An analysis using this class of models suggested that site occupancy and use by Golden Eagles Aquila chrysaetos may be influenced by disturbance from human hikers (Martin et al. 2009). Pilot attempts to fit such models to our data resulted in poorly converged models, suggesting that our current data set is too sparse to use such models. However, increasing the sample size with several more years of observations might improve our data set sufficiently to use these more complex and potentially informative models.

\section{Implications}

The indication that increasing habitat fragmentation negatively influenced persistence in site occupancy by Southeastern American Kestrels has clear implications for management of this threatened subspecies. Many of the management practices now recommended for maintenance of longleaf pinelands, such as frequent low-intensity burns, should serve to reduce the intrusion of hardwoods or other trees, thus preserving the suitability of the landscape for kestrels (Myers and Ewel 1990). However, forests are not the only land cover type fragmenting open land cover in north-central Florida. Urbanisation is also responsible for some of the changes in land cover in recent decades, and zoning restrictions in sensitive habitats or preservation of open habitat structure in low-density urban developments might reduce the effects of ongoing urbanisation on kestrel populations. Many of the nest boxes monitored in 2008-2010 were located on utility poles within low density urban or exurban areas, and kestrels persisted at many of these sites. Learning more about why kestrels can tolerate some forms of urbanisation and increasing habitat complexity will aid in both guiding future conservation efforts for this species, and furthering our understanding of the effects of fragmentation on open habitat birds.

\section{Supplementary Material}

The supplementary materials for this article can be found at journals.cambridge.org/bci 


\section{Acknowledgements}

We thank T. Breen, R. Melvin, K. Miller, and B. Millsap for the nest box network. M. Brown, K. Meyer, and G. Zimmerman assisted in the field. The manuscript was greatly improved by comments from the referees. Financial support was provided by the Eastern Bird Banding Association, Florida Ornithological Society, Raptor Research Foundation, Sigma Xi, and the University of Nevada, Reno Program in Ecology, Evolution, and Conservation Biology.

\section{References}

Askins, R. A., Chávez-Ramírez, F., Dale, B. C., Haas, C. A., Herkert, J. R., Knopf, F. L. and Vickery, P. D. (2007) Conservation of grassland birds in North America: understanding ecological processes in different regions. Ornithol. Monogr. 64: 1-46.

Bayard, T. S. and Elphick, C. S. (2010) How area sensitivity in birds is studied. Conserv. Biol. 24: 938-947.

Bohall-Wood, P. and Collopy, M. W. (1986) Abundance and habitat selection of two American Kestrel subspecies in north-central Florida. Auk 103: 557-563.

Brennan, L. A. and Kuvlesky, W. P, Jr.. (2005) North American grassland birds: an unfolding conservation crisis? J. Wildl. Manage. 69: $1-13$.

Cabe, P. R. (1993) European starling (Sturnus vulgaris). In A. Poole, ed. The birds of North America online. Ithaca, NY, USA: Cornell Lab of Ornithology.

Chalfoun, A. D., Thompson, F. R., III and Ratnaswamy, M. J. (2002) Nest predators and fragmentation: a review and meta-analysis. Conserv. Biol. 16: 306-318.

Collopy, M. W. (1996) Southeastern American Kestrel, Falco sparverius paulus. Pp. 211-218 in J. A. Rodgers, H. W. I. I. Kale and H. T. Smith, eds. Rare and endangered biota of Florida. Vol. V: birds. Gainesville, Florida: University of Florida Press.

Connor, E. F. and McCoy, E. D. (1979) The statistics and biology of the species-area relationship. Am. Nat. 113: 791-833.

Cunningham, M. A. and Johnson, D. H. (2006) Proximate and landscape factors influence grassland bird distributions. Ecol. Appl. 16: 1062-1075.

Curtis, O. E., Rosenfield, R. N. and Bielefeldt, J. (2006) Cooper's Hawk (Accipiter cooperii). In A. Poole, ed. The birds of North America online. Ithaca, NY, USA: Cornell Lab of Ornithology.

Cushman, S., McGarigal, K. and Neel, M. (2008) Parsimony in landscape metrics: Strength, universality, and consistency. Ecol. Indic. 8: 691-703.

Desrochers, A., Renaud, C., Hochachka, W. M. and Cadman, M. (2010) Area-sensitivity by forest songbirds: theoretical and practical implications of scale-dependency. Ecography 33: 921-931.

Fahrig, L. (2003) Effects of habitat fragmentation on biodiversity. Annu. Rev. Ecol. Evol. Syst. 34: 487-515.

Flather, C. H. and Bevers, M. (2002) Patchy reaction-diffusion and population abundance: the relative importance of habitat amount and arrangement. Am. Nat. 159: $40-56$.

Fletcher, R. J., Jr., Ries, L., Battin, J. and Chalfoun, A. D. (2007) The role of habitat area and edge in fragmented landscapes: definitively distinct or inevitably intertwined? Can. J. Zool. 85: 1017-1030.

Florida Fish and Wildlife Conservation Commission. (2003) Florida's breeding bird atlas: A collaborative study of Florida's birdlife [WWW Document]. URL http:// www.myfwc.com/bba

Florida Fish and Wildlife Conservation Commission. (2005) Florida's wildlife legacy initiative: Florida's comprehensive wildlife conservation strategy. Tallahassee, Florida, USA: Florida Wildlife Commission.

Herkert, J. R. (1994) The effects of habitat fragmentation on midwestern grassland bird communities. Ecol. Appl. 4: 461-471.

Hoffman, M. L. and Collopy, M. W. (1983) Historical status and nest-site selection of the American Kestrel (Falco sparverius 
paulus) in Florida. Doctoral dissertation, University of Florida.

Hoffman, M. L. and Collopy, M. W. (1987) Distribution and nesting ecology of the American kestrel (Falco sparverius paulus) near Archer, Florida. Pp. 47-57 in D. M. Bird and R. Bowman, eds. The ancestral kestrel. Ste. Anne de Bellevue, Quebec: Raptor Research Foundation and MacDonald Raptor Research Centre.

Hoffman, M. L. and Collopy, M. W. (1988) Historical status of the American Kestrel (Falco sparverius paulus) in Florida. Wilson Bull. 100: 91-107.

Kautz, R., Stys, B. and Kawula, R. (2007) Florida vegetation 2003 and land use change between 1985-89 and 2003. Florida Scientist 70: 12-23.

Koenig, W. D., Gowaty, P. A. and Dickinson, J. L. (1992) Boxes, barns, and bridges confounding factors or exceptional opportunities in ecological studies. Oikos 63: 305-308.

Lunn, D. J. (2007) Automated covariate selection and Bayesian model averaging in population PK/PD models. J. Pharmacokinetics and Pharmacodynamics 35: 85-100.

Lunn, D. J., Best, N. and Whittaker, J. (2009) Generic reversible jump MCMC using graphical models. Stat. Comput. 19: 395-408.

Lunn, D.J., Thomas, A., Best, N and Spiegelhalter, D. (2000) WinBUGS - a Bayesian modelling framework: concepts, structure, and extensibility. Stat. Comput. 10: 325-337.

MacKenzie, D. I., Nichols, J. D., Hines, J. E., Knutson, M. G. and Franklin, A. B. (2003) Estimating site occupancy, colonization, and local extinction when a species is detected imperfectly. Ecology 84: 2200-2207.

MacKenzie, D. I., Nichols, J. D., Seamans, M. E. and Gutiérrez, R. J. (2009) Modeling species occurrence dynamics with multiple states and imperfect detection. Ecology 90: 823-835.

Martin, J., McIntyre, C. L., Hines, J. E., Nichols, J. D., Schmutz, J. A. and MacCluskie, M. C. (2009) Dynamic multistate site occupancy models to evaluate hypotheses relevant to conservation of Golden Eagles in Denali National Park, Alaska. Biol. Conserv. 142: 2726-2731.
Martin, T. E. (1995) Avian life history evolution in relation to nest sites, nest predation, and food. Ecol. Monogr. 65: 101-127.

McGarigal, K., Cushman, S. A., Neel, M. C. and Ene, E. (2002) FRAGSTATS: Spatial Pattern Analysis Program for Categorical Maps. Amherst: University of Massachusetts. http://www.umass.edu/landeco/research/ fragstats/fragstats.html

Miller, K. E. and Smallwood, J. A. (1997) Natal dispersal and philopatry of Southeastern American Kestrels in Florida. Wilson Bull. 109: 226-232.

Miller, K. and Smallwood, J. A. (2009) Breedingsite fidelity of southeastern American kestrels (Falco sparverius paulus). J. Raptor Res. 43: 369-371.

Møller, A. P. (1989) Parasites, predators, and nest boxes: facts and artefacts in nest box studies of birds? Oikos 56: 421-423.

Myers, R. L. and Ewel, J. J. (1990) Ecosystems of Florida, Orlando, FL, USA: University of Central Florida Press.

Plummer, M., Best, N., Cowles, K. and Vines, K. (2006) CODA: convergence diagnostics and output analysis for MCMC. $R$ News 6: 7-II.

Pollock, K. H. (1982) A capture-recapture design robust to unequal probability of recapture. J. Wildl. Manage. 46: 752-757.

Provencher, L., Gobris, N. M., Brennan, L. A., Gordon, D. R. and Hardesty, J. L. (2002) Breeding bird response to midstory hardwood reduction in Florida sandhill longleaf pine forests. J. Wildl. Manage. 66: 641-661.

Prugh, L. R., Hodges, K. E., Sinclair, A. R. E. and Brashares, J. S. (2008) Effect of habitat area and isolation on fragmented animal populations. Proc. Natl. Acad. Sci. U.S.A. 105: 20770-20775.

Pulliam, H. R. (1988) Sources, sinks, and population regulation. Am. Nat. 132: 757-785.

R Development Core Team. (2010) R: a language and environment for statistical computing.Vienna, Austria.http://www.rproject.org/

Ribic, C. A., Koford, R. R., Herkert, J. R., Johnson, D. H., Niemuth, N. D., Naugle, D. E., Bakker, K. K., Sample, D. W. and Renfrew, R. B. (2009) Area sensitivity in North American grassland birds: patterns and processes. Auk 126: $233-244$. 
Royle, J. A. and Dorazio, R. M. (2008) Hierarchical modeling and inference in ecology, Burlington, MA, USA: Academic Press.

Royle, J. A. and Kery, M. (2007) A Bayesian state-space formulation of dynamic occupancy models. Ecology 88: 1813-1823.

Sauer, J. R., Hines, J. E., Fallon, J. E., Pardieck, K. L., Ziolkowski, D L, J. and Link, W. A. (2011) The North American breeding bird survey, results and analysis 1966-2010. Version 12.07.2011. Laurel, MD: USGS Patuxent Wildlife Research Center. http:// www.mbr-pwrc.usgs.gov/bbs/bbs.html

Smallwood, J. A. and Bird, D. M. (2002) American Kestrel (Falco sparverius). In A. Poole and F. Gill, eds. The birds of North America. Philadelphia, PA: The Birds of North America, Inc.

Smallwood, J. A. and Collopy, M. W. (2009) Southeastern American Kestrels respond to an increase in the availability of nest cavities in north-central Florida. J. Raptor Res. 43: 291-300.

Smallwood, J. A. and Wargo, P. J. (1997) Nest site habitat structure of American Kestrels in northwestern New Jersey. Bull. N J Acad. Sci. 42: 7-10.

Smallwood, J. A., Causey, M. F., Mossop, D. H., Klucsarits, J. R., Robertson, B., Robertson, S., Mason, J., Maurer, M. J., Melvin, R. J., Dawson, R. D., Bortolotti, G. R., Parrish, John W Parrish, J., Breen, T. F. and Boyd, K.
(2009) Why are American Kestrel (Falco sparverius) populations declining in North America? Evidence from nest-box programs. J. Raptor Res. 43: 274-282.

Stephens, S. E., Koons, D. N., Rotella, J. J. and Willey, D. W. (2003) Effects of habitat fragmentation on avian nesting success: a review of the evidence at multiple spatial scales. Biol. Conserv. 115: 101-110.

Sturtz, S., Ligges, U. and Gelman, A. (2005) R2WinBUGS: a package for running WinBUGS from R. J. Stat. Softw. 12: 1-16.

Thornton, D. H., Branch, L. C. and Sunquist, M. E. (2011) The influence of landscape, patch, and within-patch factors on species presence and abundance: a review of focal patch studies. Landsc. Ecol. 26: 7-18.

Watling, J. I. and Donnelly, M. A. (2006) Fragments as islands: a synthesis of faunal responses to habitat patchiness. Conserv. Biol. 20: 1016-1025.

Watling, J. I., Nowakowski, A. J., Donnelly, M. A. and Orrock, J. L. (2011) Meta-analysis reveals the importance of matrix composition for animals in fragmented habitat. Glob. Ecol. Biogeogr. 20: 209-217.

Wiens, J. A. (2000) Ecological heterogeneity: an ontogeny of concepts and approaches. Pp. 9-3I in M. J. Hutchin, E. A. John and A. J. A. Stewart, eds. The ecological consequences of heterogeneity. New York: Blackwell.

\section{JESSI L. BROWN*}

Department of Natural Resources and Environmental Science and Ecology, Evolution and Conservation Biology Graduate Program, University of Nevada, Reno, MS 436, Reno, NV 89557, USA.

MICHAEL W. COLLOPY

Academy for the Environment, University of Nevada, Reno, 202 Ross Hall, Reno, NV 89557, USA.

JOHN A. SMALLWOOD

Department of Biology and Molecular Biology, Montclair State University, Montclair, NJ 07043, USA.

*Author for correspondence; e-mail: jessilbrown@gmail.com 